Article

\title{
On the Use of the Eddy Covariance Latent Heat Flux and Sap Flow Transpiration for the Validation of a Surface Energy Balance Model
}

\author{
Antonino Maltese ${ }^{1}$ (D), Hassan Awada ${ }^{1}$, Fulvio Capodici ${ }^{1}$ (D), Giuseppe Ciraolo ${ }^{1}$ (1), \\ Goffredo La Loggia ${ }^{1}$ and Giovanni Rallo ${ }^{2, *(D)}$ \\ 1 Dipartimento di Ingegneria Civile, Ambientale, Aerospaziale, dei Materiali-DICAM, Università degli Studi \\ di Palermo, Viale delle Scienze, Bld. 8, 90128 Palermo, Italy; antonino.maltese@unipa.it (A.M.); \\ hassan.awada@unipa.it (H.A.); fulvio.capodici@unipa.it (F.C.); giuseppe.ciraolo@unipa.it (G.C.); \\ goffredo.laloggia@unipa.it (G.L.L.) \\ 2 Dipartimento Scienze Agrarie Alimentari ed Agro-ambientali, Università di Pisa, Via del Borghetto, 80, \\ 56124 Pisa, Italy \\ * Correspondence: giovanni.rallo@unipi.it; Tel.: +39-050-221-6158
}

Received: 11 October 2017; Accepted: 26 January 2018; Published: 29 January 2018

\begin{abstract}
Actual evapotranspiration is assessed via surface energy balance at an hourly rate. However, a robust estimation of daily evapotranspiration from hourly values is required. Outcomes of surface energy balance are frequently determined via measures of eddy covariance latent heat flux. Surface energy balance can be applied on images acquired at different times and spatial resolutions. In addition, hourly actual evapotranspiration needs to be integrated at a daily rate for operational uses. Questions arise whether the validation of surface energy balance models can benefit from complementary in situ measures of latent heat flux and sap flow transpiration. Here, validation was driven by image acquisition time, spatial resolution, and temporal integration. Thermal and optical images were collected with a proximity-sensing platform on an olive orchard at different acquisition times. Actual latent heat fluxes from canopy and sap flux at tree trunks were measured with a flux tower and heat dissipation probes. The latent heat fluxes were then further analyzed. A surface energy balance was applied over proximity sensing images re-sampled at different spatial resolutions with resulting latent heat fluxes compared to in situ ones. A time lag was observed and quantified between actual latent heat fluxes from canopy and sap flux at the tree trunk. Results also indicate that a pixel resolution comparable to the average canopy size was suitable for estimating the actual evapotranspiration via a single source surface energy balance model. Images should not be acquired at the beginning or the end of the diurnal period. Findings imply that sap flow transpiration can be used to measure surface energy balance at a daily rate or when images are found at an hourly rate near noon, and the existing time lag between the latent heat flux at the canopy and the sap flow at the trunk does not need to be taken into account.
\end{abstract}

Keywords: flux tower; heat dissipation technique; time lag; spatial resolution; acquisition time

\section{Introduction}

An accurate estimation of agricultural water is essential since it accounts for $70 \%$ of total global freshwater withdrawals and is expected to increase a further $10 \%$ by 2050 [1]. Thus, implementing wise agricultural water practices is an important task for global hydrologic cycle management. For precision irrigation, both the amount and timing of water supply are important. These can be obtained using criteria of plant physiological status such as the plant water potential needed to manage the water stress of the crop. An inverse relationship exists between predawn leaf water potential and the ratio between 
actual and reference evapotranspiration [2]. On the other hand, remote-sensing-based energy balance models allow for characterization of the spatial distribution of actual hourly evapotranspiration, $E T\left(\mathrm{~mm} \cdot \mathrm{d}^{-1}\right)$. This allows for the extension of point-based to spatially distributed water potential.

The best known and widely accepted methodology for validating surface energy balance models is the eddy covariance (EC), which allows for the measurement of both latent heat flux, $\lambda E T\left(\mathrm{~W} \cdot \mathrm{m}^{-2}\right)$, and sensible heat flux, $\mathrm{H}\left(\mathrm{W} \cdot \mathrm{m}^{-2}\right)$ [3]. Some authors [4] have demonstrated that the joint use of eddy covariance and sap flow (SF) techniques is effective for evaluating the components of evapotranspiration in orchards (i.e., olive trees).

Surface energy balance estimations can be validated by comparing micro-meteorological measures (e.g., acquired by flux towers, FT) and eco-physiological sensors (e.g., sap flow). More specifically, sap flow is based on a heat dissipation technique [5] suited to measure canopy transpiration. Flux towers, on the other hand, are based on the eddy covariance technique [6], which provides an estimation of the sum of surface evaporation (coincident with soil evaporation over dry canopy) and canopy transpiration.

Surface energy balance models can estimate instantaneous flux values using images acquired at different times and spatial resolutions. Instantaneous values are assumed to represent hourly fluxes. For operational purposes, actual evapotranspiration needs to be estimated over longer time periods. Several methods have been proposed to time-scale instantaneous $\lambda E T$ into evapotranspiration daily values, $E T_{D}\left(\mathrm{~mm} \cdot \mathrm{d}^{-1}\right)$ (from now on, the subscript " $D^{\prime \prime}$ indicates daily variables) [7]. Several authors (e.g., $[8,9])$ use a method based on two main hypotheses:

(i) the evaporative fraction at the acquisition time, $\Lambda(-)$, is assumed equal to its average diurnal value; in other words, the fraction of available energy used for the evapotranspiration process is almost constant during diurnal hours (self-preservation hypothesis);

(ii) the daily soil heat flux at ground level can be neglected when compared to the daily net radiation, $R_{n, \mathrm{D}}$, since, during a day cycle, daytime heat flux almost balances the nighttime one.

These two hypotheses are uncertain for the estimation of daily evapotranspiration, so the application of this time-scaling approach might be limited under certain meteorological conditions. Changes in temperature, humidity, and wind speed may play a prominent role when partitioning the energy budget, and intermittent cloudiness may cause a significant change in $\Lambda[9,10]$. However, Crago [10] showed that the self-preservation hypothesis is surprisingly robust on clear-sky days.

An alternative and simple upscaling approach hypothesizes a proportionality between evapotranspiration and incoming shortwave radiation, $R_{S}\left(\mathrm{~W} \cdot \mathrm{m}^{-2}\right)$, during the whole day [11], which can be applied in partially clear-sky conditions as well.

The main objective of this research was to assess whether or not evaporation and transpiration fluxes can be determined at hourly and daily scales using flux towers and sap flow measures. The research also aimed to point out the advantages and limitations of each technique. The analysis was carried out by applying two different time-scale methods to data obtained at varying spatial resolutions and different times.

To this goal, latent heat flux and sap flux were monitored at an olive orchard by deploying a flux tower and heat dissipation probes for fruit development and berry growth stages. At the end of the investigation period, an experimental platform, equipped with thermal and optical radiometric cameras, was used to estimate the spatial distribution of latent heat flux via surface energy balance.

\section{Methods}

Latent heat flux estimated via surface energy balance models can be validated via eddy covariance and sap flow measurements. Other measurements are based on scintillometry, lisimetry, and surface renewal (e.g., [12-14]). 


\subsection{The Surface Energy Balance Model}

Latent heat flux can be determined as a residual term of the surface energy balance equation:

$$
\lambda E T=\left(R_{n}-G_{0}\right)-H
$$

where $R_{n}, G_{0}$, and $H$ are, respectively, the net radiation, the ground heat, and sensible heat fluxes at the acquisition time $\left(\mathrm{W} \cdot \mathrm{m}^{-2}\right)$; the difference $\left(R_{n}-G_{0}\right)$ is the available energy [15].

SEBAL is a single-source surface energy balance model schematizing soil-vegetation as a sole resistance layer $([8,16,17])$. $E T_{D}$ is extrapolated from hourly values using $\Lambda$ as an integration parameter.

$$
\Lambda=\frac{\lambda E T}{R_{n}-G_{0}} .
$$

The diurnal average evaporative fraction, $\Lambda_{\mathrm{d}}$, is obtained by increasing $\Lambda$ by $10 \%$ [15] to account for the $\Lambda$ temporal behavior during cloudless days. Indeed, hourly $\Lambda$ usually exhibits a slightly concave-up shape [18] characterized by a minimum near solar noon and two maxima near sunrise and sunset (with high variability before and after sunrise and sunset, respectively).

The use of $\Lambda_{d}$ implies that nighttime $\lambda E T$ is small and thus negligible compared to daily $\lambda E T$ [9]. Accordingly, Malek [19] found that nighttime $\lambda E T$ (from sunset to sunrise) was $1.7 \%$ of $\lambda E T_{D}$ during a complete growing cycle of alfalfa. However, this ratio increased up to $14 \%$ when the nighttime wind speed was high.

The instantaneous daily integration process assumes that during a daily cycle the sum of incoming and outgoing ground heat fluxes is negligible compared to the daily net radiation [8]. It also assumes that $\Lambda$ can be supposed as a constant if limited to only diurnal hours of cloudless days (evaporative fraction self-preservation).

Although this latter assumption has been documented (e.g., $[17,20])$, it could lead to the underestimation of $E T_{D}$ in arid climates where afternoon advection (or increased afternoon wind speed) may increase $\lambda E T$ in proportion to available energy [21]. Diurnal course of $\Lambda$ responds to several factors including the relative amplitude of turbulent heat fluxes. The validation of $\lambda E T$ by using the difference between the $G_{0}$ and $R_{n}$ (the available energy) explains the $\Lambda$ daily shape. In addition, the daytime behavior of $\Lambda$ depends on environmental factors including a sharp rise in soil water content and leaf area index, $L A I\left(\mathrm{~m}^{2} \cdot \mathrm{m}^{-2}\right)$ [22].

Due to these factors, the inherent concave-up shape of $\Lambda$ causes underestimation of daily evapotranspiration if the instantaneous evaporative fraction value is assumed to represent the diurnal average value. Experimental work (e.g., $[23,24]$ ) has also demonstrated that the self-preservation hypothesis holds true for environmental conditions where soil water content does not significantly change and advection does not occur.

According to Chàvez et al. [7], the upscaling of $E T$ to $E T_{D}\left(\mathrm{~mm} \cdot \mathrm{d}^{-1}\right)$, under the hypothesis of self-preservation of $\Lambda$, is obtained as follows:

$$
E T_{D, \Lambda} \approx \frac{86,400 R_{n, D}}{\lambda \rho_{W}}
$$

where 86,400 is a time unit conversion factor $\left(\mathrm{s} \cdot \mathrm{d}^{-1}\right)$ for $E T_{D}, \lambda$ is the latent heat of vaporization $\left(\mathrm{MJ} \cdot \mathrm{Kg}^{-1}\right)$, and $\rho_{w}$ is the water density $\left(\mathrm{kg} \cdot \mathrm{m}^{-3}\right)$.

The second approach estimates the $E T_{D}$ using $R_{S}$ as a reference integration variable [25] under the hypothesis of proportionality between $E T$ and $R_{S}$ at a daily scale. Even though this approach requires the measurement of solar irradiation as additional input, it is sometimes preferred to Equation (3), which can have inaccuracies associated with the variability of cloud presence (Equation (4)):

$$
E T_{D, \mathrm{R}_{\mathrm{S}}} \approx E T \frac{R_{S, D}}{R_{S}}
$$




\subsection{The Flux Time-Scaling via Micro-Meteorological Measurements}

Integration based on $\Lambda$ self-preservation hypothesis was tested using EC tower data. $R_{n}$ is obtained by balancing short-wave and long-wave radiations measured through a four components net radiometer. $G_{0}$ is measured through a self-calibrating soil heat plate. $\lambda E T$ is calculated based on the covariance between the vertical velocity fluctuation of wind and the water vapor density.

$H$ and $\lambda E T$ were derived from high frequency sonic air temperature and water vapor concentration. Both $H$ and $\lambda E T$ were determined in phase with three-dimensional wind speed measurements, according to the eddy covariance [6]. $H$ and $\lambda E T$ were adjusted by introducing several corrections to raw data, as described in Cammalleri et al. [9].

However, failure in the closing of the surface energy balance often occurs due to several factors, including the averaging and coordination of rotation periods, a difference in the fluxes source areas, and an influence on the low-frequency part of the turbulence spectra [26]. Thus, surface energy balance components were adjusted by including the energy closure with the goal of preserving the Bowen ratio, $\beta_{R}=H \cdot \lambda E T^{-1}$ [27]. Measures that have a surface energy balance closure error within $\pm 15 \%$ were considered reliable [28]. According to Schuepp et al. [29], the cumulative normalized contribution to the flux measurements allowed for estimation of the upwind distance, which gave a significant fraction of fluxes (e.g., $70 \%$ of the fluxes, $F P_{0.70}(\mathrm{~m})$ ), as well as the distance for the maximum flux contribution, $X_{\max }(\mathrm{m})$.

\subsection{Tree Transpiration Measurement: The Heat Dissipation Technique}

Tree transpiration can be estimated via the heat dissipation technique [30] by measuring the sap velocity of the woody stems (5):

$$
T_{P}=\frac{1}{A_{P}} \sum_{t=0}^{24} q d t=\frac{S}{A_{P}} \sum_{t=0}^{24} \alpha\left(\frac{\Delta T_{\max }-\Delta T}{\Delta T}\right)^{\beta} d t
$$

The plant transpiration $T_{p}(\mathrm{~mm})$ is obtained by measuring the temperature difference, $\Delta T(\mathrm{~K})$, between a heated upper probe and an unheated lower probe radially inserted into the trunk to intercept the sapwood. The faster the sap fluxes, $q\left(\mathrm{~m}^{3} \cdot \mathrm{s}^{-1}\right)$, the more the heat dissipates and the lower $\Delta T$. When sap flux rate is negligible (during night time) $\Delta T$ is the maximal, $\Delta T_{\max }$. This approach allows for estimation of the $q$ of a single plant by multiplying the sap flow velocity for the cross-sectional area of the sapwood, $S\left(\mathrm{~m}^{2}\right) ; q$ is then upscaled through a plant pertinence area, $A_{p}\left(\mathrm{~m}^{2}\right)$. The coefficients $\alpha$ and $\beta$ are assumed to be equal to $0.714 \mathrm{~ms}^{-1}$ and 1.213, respectively [5]. The daily volume of water consumed by a single plant is determined via daily integration every half hour, called the time step, $t$, assuming the effect of the tree capacity at the daily time interval is negligible [31].

A further scaling step was required to evaluate a representative value of the stand transpiration over a plot, $T(\mathrm{~mm})$, from that of individual plants.

$$
T_{P}=\bar{T}_{P} \frac{L A I}{\overline{L A I}_{P}}
$$

In particular, $T_{p}$ was upscaled by considering, as a proximal variable, the ratio between the average plot $L A I$ and the $L A I$ of the single plants, $L A I_{p}\left(\mathrm{~m}^{2} \cdot \mathrm{m}^{-2}\right)$, in which sap flow was monitored, and where overbars denote average values (Equation (6)).

\subsection{Eddy Covariance and Sap-Flow Diurnal Behavior and Time Lag between EC and SF Measurements}

Comparing sap flow and eddy covariance measurements is necessary for analyzing the daily behavior of transpiration $T$ and ET. Although EC data are sampled at high frequency $(20 \mathrm{~Hz})$, measurements are processed on a half-hour scale. Thus, the SF time series were averaged accordingly. Data normalization was applied to take into account upscaling inaccuracies of SF measurements and scale mismatching among the tree canopies sap flow and the eddy covariance footprint. By dividing 
each measurement by the total (e.g., the sum of measurements of the whole day), this normalization standardizes and scales the measurements. This allows for the comparison between the diurnal behavior of $E T$ and $T$ during the studied period. The average daily behavior (1-day cycle) of $E T$ vs. $T$ was derived by averaging $30 \mathrm{~min}$ measurements. This was completed for a 5-week period from 29 June, 12:00 p.m., to 2 August, 11:00 p.m. UTC (all times are reported in UTC). Finally, the determination coefficient, $r^{2}(-)$, between the daytime measures of ET and $T$, was maximized by shifting forward in time the latter time series, allowing for the quantification of the time lag between $T$ at the trunk and ET at the canopy.

\subsection{The Surface Energy Balance Model Validation}

The micro-meteorological measurements of $\lambda E T$ were used to validate remote sensing surface energy balance estimations over the flux tower footprint. To figure out whether soil evaporation was negligible, sap flow measures (i.e., $T$ ) were compared with FT measures (i.e., ET).

The absolute difference, $A D(-)$, was calculated as evaluation metric (7):

$$
A D=\frac{\lambda E T-\lambda E T_{\beta_{R}}}{\frac{\lambda E T+\lambda E T_{\beta_{R}}}{2}} ; \quad A D_{\Lambda}=\frac{\lambda E T_{D, \Lambda}-\lambda E T_{D, \beta_{R}}}{\frac{\lambda E T_{D, \Lambda}+\lambda E T_{D, \beta_{R}}}{2}} ; \quad A D_{\Lambda}=\frac{\lambda E T_{D, R_{\mathrm{S}}}-\lambda E T_{D, \beta_{R}}}{\frac{\lambda E T_{D, R_{\mathrm{S}}}+\lambda E T_{D, \beta_{R}}}{2}} \quad(7 \mathrm{a}, \mathrm{b}, \mathrm{c})
$$

where $A D$ (7a) indicates $\lambda E T$ absolute differences compared to eddy covariance $\lambda E T$ closed with the Bowen ratio approach; $A D_{\Lambda}$ and $A D_{R s}$ indicate absolute daily $E T_{D}$ difference based on Equations (3) and (4), respectively.

For the absolute difference calculations, eddy covariance $\lambda E T$ and $E T_{D}$ were adjusted, which forced the energy closure by preserving the value of the Bowen ratio, $\beta_{R}$.

\subsection{Spatial Resolution Analysis}

Both remote-sensing-based $\lambda E T$ and $E T_{D}$ retrievals vary depending on the spatial resolution, which impacts the validation of surface energy balance models with micro-meteorological or sap flow data. To quantify these effects, original multi-spectral and thermal images were downscaled from the raw resolutions to coarser resolutions characterizing the canopy sizes of the orchard trees. Thus, the average of the footprint area was compared with FT fluxes and with upscaled $T$ obtained using SF measures.

To verify whether $\lambda E T$ values can represent hourly values, a coefficient of variation, $C V$ (unitless), was evaluated over half-hourly EC $\lambda E T$ measures. The $C V$ is computed over time by applying a $1 \mathrm{~h}$ moving window (3 values); $C V$ is then assigned to the median acquisition time.

\section{Materials}

\subsection{The Experimental Farm}

The "Tenuta Rocchetta-Azienda Agricola Angela Consiglio" experimental farm (Figure 1) is located along the southwest coast of Sicily, Italy. The farm lies several kilometers southeast of the Castelvetrano town by the lower Belice river valley. The district is mostly agricultural and is characterized by a typical Mediterranean climate with moderate rainfall in the autumn and winter seasons and where the summer remains hot and dry. The farm has a 2 ha olive orchard (Nocellara del Belice cultivar). Olive is the main crop in the district.

Trees are planted on a regular grid of $8 \times 5 \mathrm{~m}\left(250\right.$ plants $\cdot \mathrm{ha}^{-1}$ and a plant pertinence area equal to $40 \mathrm{~m}^{2}$ ). The olive canopies are characterized by an average height of $\approx 3.3 \mathrm{~m}$, an average fraction of vegetation cover of $\approx 0.35 \mathrm{~m}$, and a canopy size ranging between $\approx 2.1$ and $\approx 5.6 \mathrm{~m}$ (on average $\approx 4.5 \mathrm{~m}$ ). A flat landscape and homogeneous soil characterize the study area. The soil is called silty clay loam (according to the United States Department of Agriculture-USDA classification), with $60 \%$ of the soil in the form of sand and $24 \%$ in the form of clay. Due to significant evaporation in the summer 
season and the near absence of rainfall during the crop season, agricultural fields are occasionally irrigated (aid irrigation). Water is supplied by a drip irrigation system (four emitters per plant, each flowing $\sim 8 \mathrm{lit} \cdot \mathrm{h}^{-1}$ of water). An eddy covariance system and sap flow sensors are installed in the olive orchard (Figure 1) to monitor the evapotranspiration and transpiration processes, respectively.

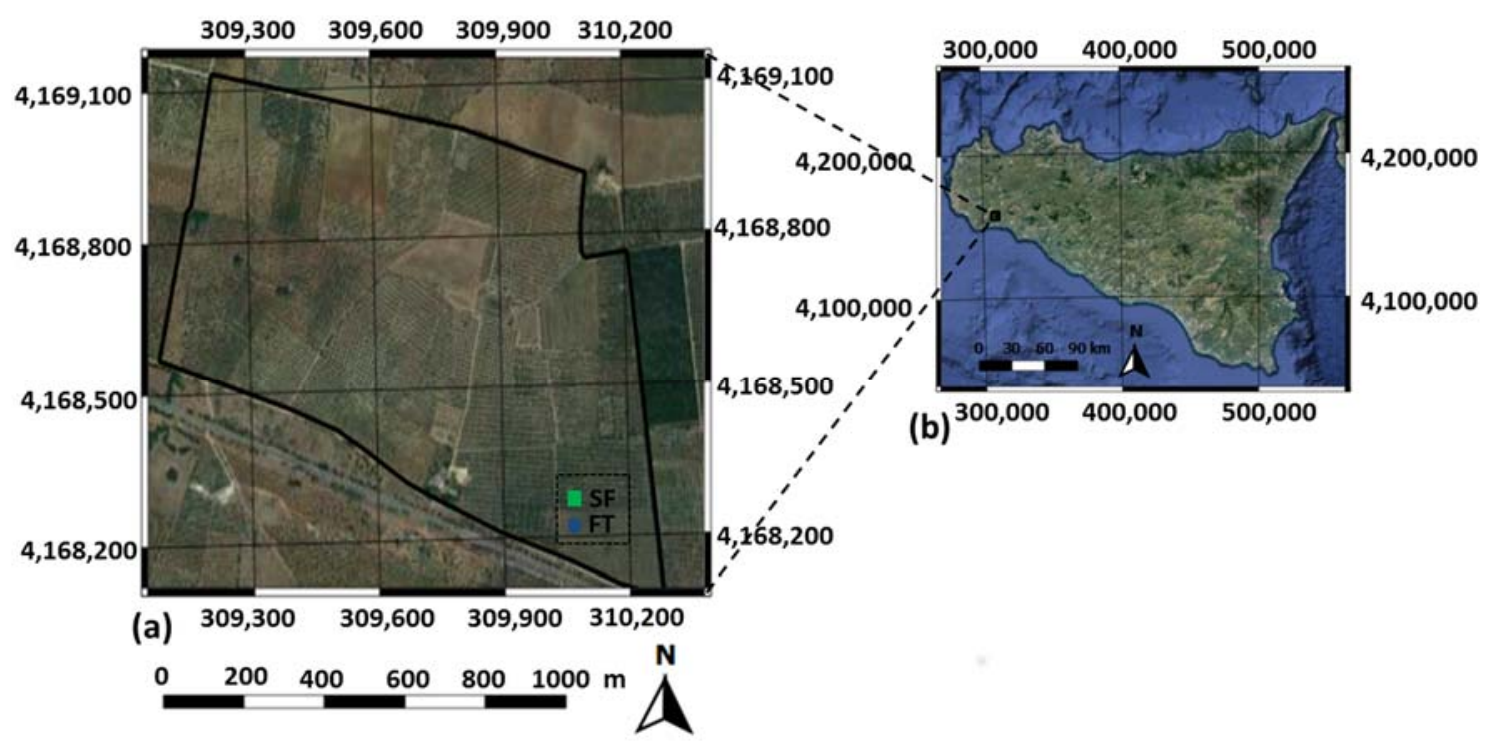

Figure 1. (a) Geographical location of the experimental fields; the continuous black boundary has average coordinates of lat.: $37.6424^{\circ}$; long: $12.8464^{\circ}$; UTM WGS 84 , which is close to the town of Castelvetrano, in the island of (b) Sicily, Italy. The blue dot and green square indicate the positions of FT and the average position of SF stations, respectively.

Eco-physiological and micrometeorological data were pre-processed in order to dispose of a data set distributed during the mid-season from June to the first week of September, which corresponds from the initial fruit development stage to the berry growth stage.

\subsection{In Situ Measurements: Sensors and Data}

Proximity sensing platform-The acquisition system encompassed an MCA-II multispectral camera (TETRACAM Inc.: Chatsworth, CA, USA) and an A320G thermal camera (FLIR system Inc.: Wilsonville, Oregon, USA). The multispectral camera is an 8 bit 6 bands CCD sensor with customized optical filters set up at $450,650,720$, and $800 \mathrm{~nm}$. The field of view was $43^{\circ} \times 35^{\circ}$. The A320G micro-bolometric thermal camera acquired thermal infrared images in the spectral broadband range of 7.5-13 $\mu \mathrm{m}$ when the field of view was $45^{\circ} \times 34^{\circ}$.

A remote laptop, which was connected to an on-board mini personal computer, controlled both cameras. The acquisition instruments were installed on an $8 \mathrm{~m}^{3}$ helium balloon (Figure 2) flying at $120 \mathrm{~m}$ above ground level (a.g.l.). The balloon was secured to the ground through three Kevlar ${ }^{\circledR}$ ropes. Afterward, the balloon was slowly let go. An ASD Field Spec Hand-Held spectroradiometer (Analytical Spectral Device, Inc., Boulder, CO, USA) enabled the study of ground reflectance between 325 and $1075 \mathrm{~nm}$, which were used for in-reflectance calibration at the ground level.

Images were acquired on 1 August 2009 at spatial resolutions of $0.12 \mathrm{~m}$ (multispectral) and $0.50 \mathrm{~m}$ (thermal infrared). Reflectance was re-sampled using pixel combinations at 2, 5, and $10 \mathrm{~m}$ to analyze the "suitable" structural resolutions for evapotranspiration retrievals at plant and plot scales. Radiant exitance emitted by the soil-vegetation system (assumed as a grey body) and recorded by the thermal sensor was re-sampled at lower spatial resolutions and converted into kinetic temperature. 


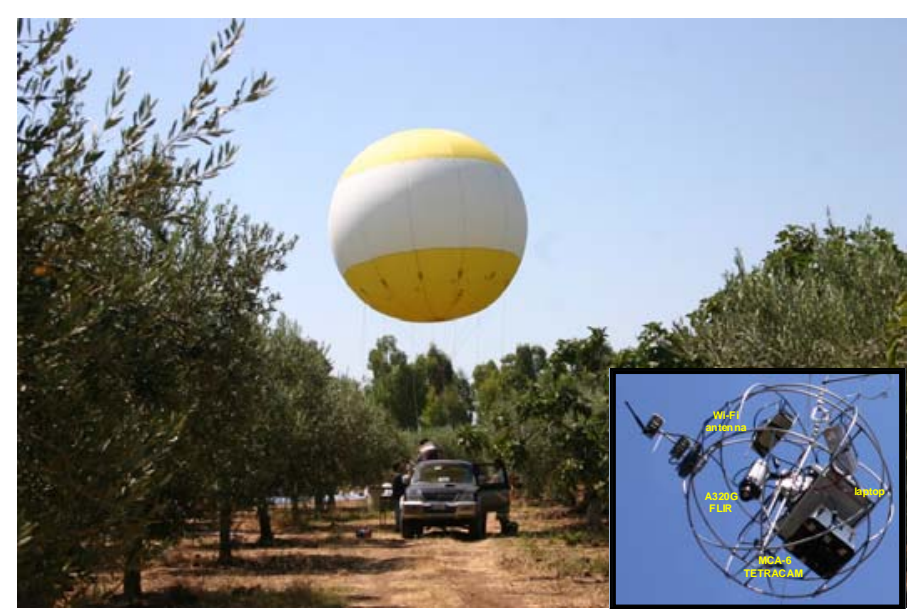

Figure 2. The tethered helium balloon during the launching phase. In the inset (lower right corner), there is an image of the proximity-sensing platform, which includes an MCA-II multispectral camera, an A320G thermal camera, a mini PC, and a wireless Wi-Fi omnidirectional antenna.

Flux tower-The flux tower installed in the olive orchard (37.64294 ${ }^{\circ}$ Lat., $12.84710^{\circ}$ Lon.) allowed for the monitoring of $H$ and $\lambda E T$ via the eddy covariance technique. The flux tower was equipped with several probes. A three-dimensional sonic anemometer (CSAT3-3D, Campbell Scientific Inc. Logan, UT, USA) was used to measure high-frequency winds at $5.6 \mathrm{~m}$ a.g.l. An infrared open-path gas analyzer (IRGA LI7500, Li-COR Biosciences Inc. Lincoln, NE, USA) measured high-frequency densities of water vapor and carbon dioxide at the same height of the sonic anemometer.

A four-component net radiometer (NR-Lite-L, Kipp and Zonen-Delft, Netherlands) positioned at an elevation of $8.5 \mathrm{~m}$ a.g.l. was used to measure direct shortwave and longwave radiations along with reflected shortwave and longwave radiations. Two soil heat flux plates (HFP01SC self-calibrating heat flux sensor, Hukseflux Thermal sensors-Delft, Netherlands) installed at a depth of $0.1 \mathrm{~m}$ below ground level (b.g.l.) were used to measure the ground heat flux. Two pyranometers (IRTS-P, IR Precision Infrared Thermocouple Sensor, Apogee Instruments, Inc.-Logan, UT, USA) installed at $4.80 \mathrm{~m}$ a.g.l. were used to measure both soil and vegetation radiometric temperature.

Sap flow-Sap flow measurements provided direct estimates of transpiration every $15 \mathrm{~min}$ on three olive trees. In particular, the heat dissipation method measured half an hour of sap velocity. Three olive trees (namely $\mathrm{P}_{1}, \mathrm{P}_{2}$, and $\mathrm{P}_{3}$ ) located close to the flux tower (Figure 1 ) were monitored. Measurements were carried out using two standard thermal dissipation probes. The main probe used was the Sapflow Sensor (SFS2 Type M-M; UP GmbH), which was installed into the trees' trunks at a height of $\approx 0.4 \mathrm{~m}$ a.g.l. According to prior footprint analysis, trees were selected at an average distance from the FT approximately equal to the daily maximum $X_{\max }$. Trees were selected according to their trunk diameter [32] to be representative of the experimental plot. The trunk diameters of $P_{1}, P_{2}$, and $\mathrm{P}_{3}$ were $0.18,0.23$, and $0.30 \mathrm{~m}$, respectively.

The probes were installed on the north side of the olive trees trunk and then insulated (Figure 3b) to avoid direct sun exposure.

To convert sap fluxes into tree transpiration, a relationship between the cross-sectional area of conducting sapwood and trunk diameter was found by coloring the sapwood area. Indeed, at the end of the experiment, the sapwood area was determined using a color-based method on a total of six wood cores extracted with a Pressler gimlet on the monitored trees. To enhance the difference between sapwood and heartwood, the conductive section of the wood adding methyl-orange to the wood core was identified. Each image of colored wood core was then analyzed with software Image-Pro Plus 6.0 (Media Cybernetics Inc.: Rockville, Maryland, USA) to define the sapwood depth. 
The values of $L A I$ and $L A I_{\mathrm{p}}$ were estimated from in situ observations collected by means of a Licor LAI-2000 Plant Canopy Analyzer (LI-COR ${ }^{\circledR}$ Biosciences): $L A I$ was $\approx 0.89 \mathrm{~m}^{2} \cdot \mathrm{m}^{-2}$, whereas $L A I_{\mathrm{p}}$ was $\approx 1.27 \mathrm{~m}^{2} \cdot \mathrm{m}^{-2}$, on average.

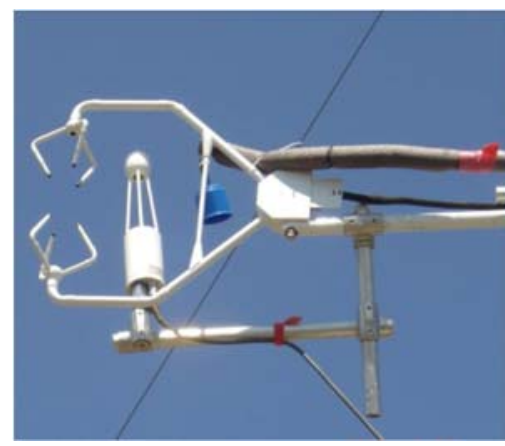

(a)

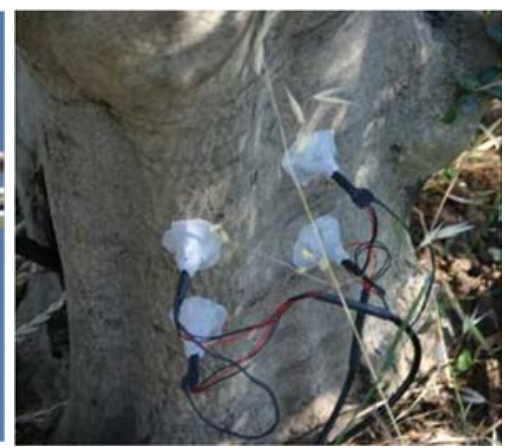

(b)

Figure 3. 3D Sonic anemometer and an infrared gas analyzer (IRGA) (a) and SF probes (b).

\section{Results and Discussion}

\subsection{Fluxes Temporal Behavior}

The $30 \mathrm{~min}$ SF values were averaged over a week and normalized over the daily total. These values show a circadian pattern characterized by a saturation-type response. $T$ and ET diurnal changes (Figure 4, black and empty dots, respectively) are nearly similar during the $24 \mathrm{~h}$ cycle with a considerable time shift. At noon, SF fluxes were nearly steady, while FT ones followed the daily trend of atmospheric evapotranspiration demand.
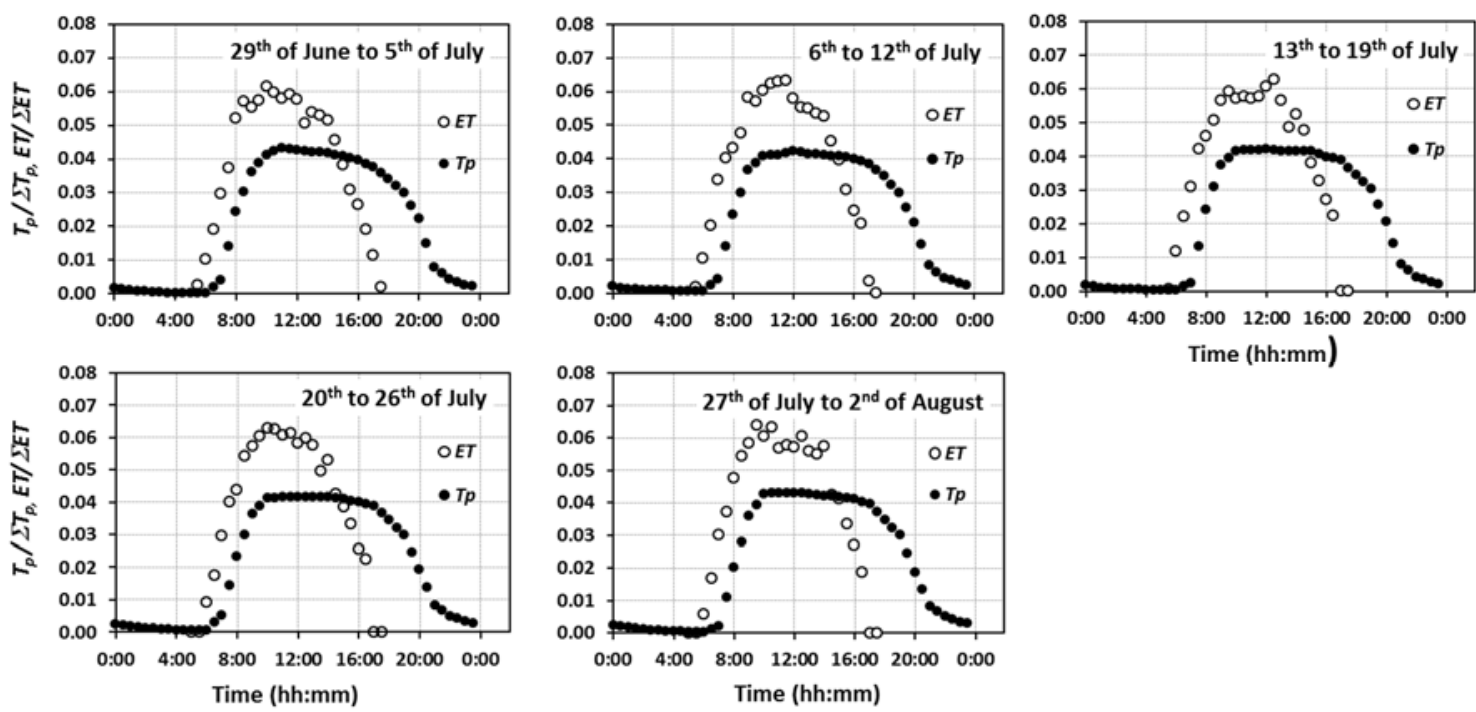

Figure 4. The 30 min normalized upscaled Tp measured with SF (black dots) and 30 min normalized diurnal ET measured with the EC tower (empty dots) averaged over a week. Data points represent the three-tree average transpiration averaged over a week. Nocturnal values of normalized EC $\lambda E T$ are not shown because of the inaccurate measurements of small fluxes.

In particular, the daily behavior of $T$ is smoother than that observed for $E T$, which rapidly varies due to meteorological forces. The observed time lag confirmed the outcomes of other studies [33-35]. If there is a large capacitive exchange between the transpiration stream and stem water storage, there 
is a significant time lag between SF measured at the base of the stem and $T$ (at the canopy leafs). Moreover, the differences between sap flow transpiration and flux tower evapotranspiration highlight an imbalance between canopy transpiration and tree water uptake.

Figure 4 shows that the diurnal cycles may be represented by two phases. The first phase, before 2:30 p.m., where $E T$ is higher than $T$, can be attributed to limited soil water content or tree capacitance when the tree is using water stored in the trunk. The second phase is after 2:30 p.m., where ET decreases and $T$ preserves a steady phase and high values. These differences in water use dynamics could be interpreted as an effect of tree capacitance.

The amount of water stored in the stem introduces uncertainty when estimating diurnal whole-tree canopy transpiration and SF transpiration measured at the base of the stem. Motisi et al. [31] showed that this imbalance between canopy transpiration and tree water uptake is recovered during the night and is likely attributable to tree capacitance. Other studies have shown that, when the stem capacitance is large, an abundance of nighttime water recharges into the stem because whole-tree transpiration is higher than the stem $q$ around mid-day [28,34,36-38].

Since $T$ exhibits almost a flat behavior close to its maximum value (Figure 4), surface energy balance outcomes can be directly measured using SF values if remote sensing images are acquired close to midday (without taking into account any time lag). It would be different if imaging and subsequent measurement were performed at the beginning or the end of the diurnal period (e.g., the 8:25 a.m. image acquisition of this experiment). Finally, uncertainties about using $T$ measurements to validate the surface energy balance estimates from remote sensing arise from the individual shape of the two curves $\left(T_{p}\right.$ and $\left.E T\right)$.

The daily cumulative upscaled sap flow $T$ was compared to the flux tower $\lambda E T_{D}$ for the day of remote sensing acquisition. The diurnal changes of $T$ (Figure 5, black dots) and ET derived by FT (Figure 5, empty dots) show, again, the time lag between those different measurements. ET and $T$ had a considerable time shift; moreover, $E T$ is slightly greater than $T$ at the end of the day when the daily cumulative values are $2.7 \mathrm{~mm}$ and $2.55 \mathrm{~mm}$ for $E T$ and $T$, respectively, where $T \approx 95.5 \%$ of $E T$.

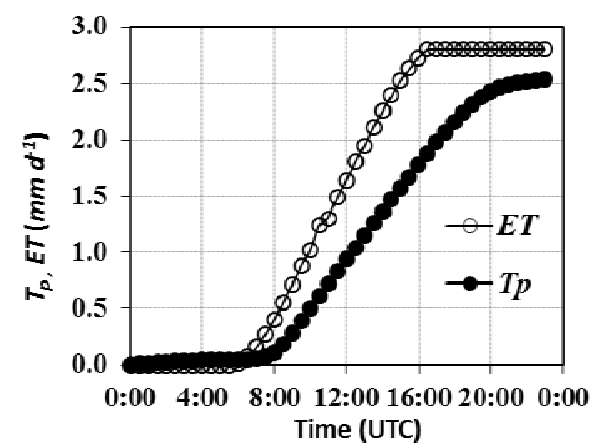

Figure 5. The daily cumulative upscaled SF Tp and EC ET during the image acquisition day. Each data point of transpiration represents the upscaled average of three trees.

Dichio et al. [39] pointed out an adaptive advantage for plants growing in semi-arid climates, such as olive trees. This adaptation allows them to maintain constant evapotranspiration rates even with low soil water content. Indeed, the high values of $T$ /ET is consistent with the olive trees large capacity for osmotic adjustment under low soil water content [40], letting the plant keep high transpiration rates.

The forward time-shifting of $T$ led to measuring the time lag between transpiration flux passing through the trunk section and latent heat flux through the canopy. In particular, the maximum determination coefficient took place for a time shift of $\approx 2.5 \mathrm{~h}$ (Figure 6 ), which can be assessed as a daily average time lag. This finding highlights that the measurement of remote sensing estimated through SF transpiration values should consider the time lag required by the sap to reach the canopy and finally evaporate. Thus, it should be considered canopy-specific. 


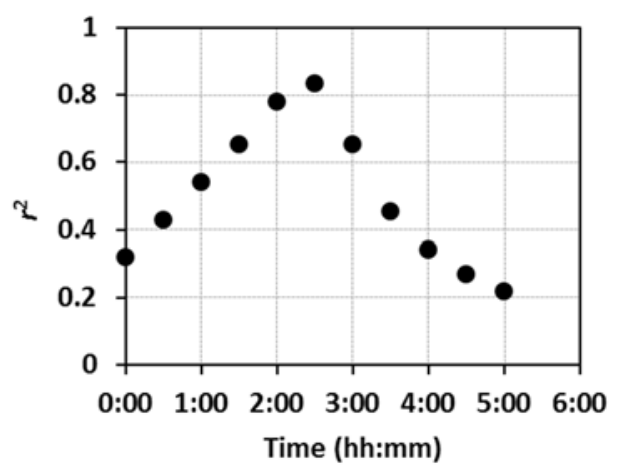

Figure 6. The coefficient of determination, $\mathrm{r}^{2}$, between EC evapotranspiration and time-shifted upscaled SF transpiration during the image acquisition day.

Surely, $T$ measurement can be used for validation if the soil evaporation is negligible, or if the validation of $E T$ is on a daily scale base. Additionally, $T$ seems less "noisy" and more stable compared to the FT measurement. As such, it has to be highlighted that, in this case, SF measurement needs to be accurately upscaled.

Since the average footprint that determine $70 \%$ of the fluxes, $F P_{0.70}$, ranges between 60 and $110 \mathrm{~m}$, and is much larger than the images' spatial resolution (i.e., original spatial resolutions were of $0.12 \mathrm{~m}$ and $0.50 \mathrm{~m}$ for multi-spectral and thermal images, respectively), spatially averaged $\lambda E T$ values at the plant scale were compared to hourly transpiration $T$ and its daily value (measured through SF).

The comparison was limited to 2 and $5 \mathrm{~m}$ spatial resolutions since fully vegetated pixels cannot be selected using $10 \mathrm{~m}$ spatial resolution images. During the experiment, the day cycle of $\Lambda$ exhibited a typical concave-up shape (Figure 7) with an average daily value of 0.58 (if calculated between 5:00 a.m. and 5:00 p.m.). Indeed, $\Lambda$ behaves according to the relative amplitude and phase of the $H$ and $\lambda E T$ harmonics [41]. In particular, when no phase difference occurs between the turbulent fluxes, diurnal $\Lambda$ exhibits a typical symmetric concave-up shape. However, when the phase difference occurs, the behavior becomes asymmetric. The $\Lambda$ values are nearly constant during mid-day with two peaks near sunrise and sunset, which is when $\Lambda$ deviates and increases sharply. Excluding the sunrise and sunset peaks, the average value was about 0.50 . At 11:00 a.m., $\Lambda$ has a minimum of 0.15 , which might be attributed to several factors, including excessive solar radiation, deviation from the optimal air temperature, and/or very low soil water content.

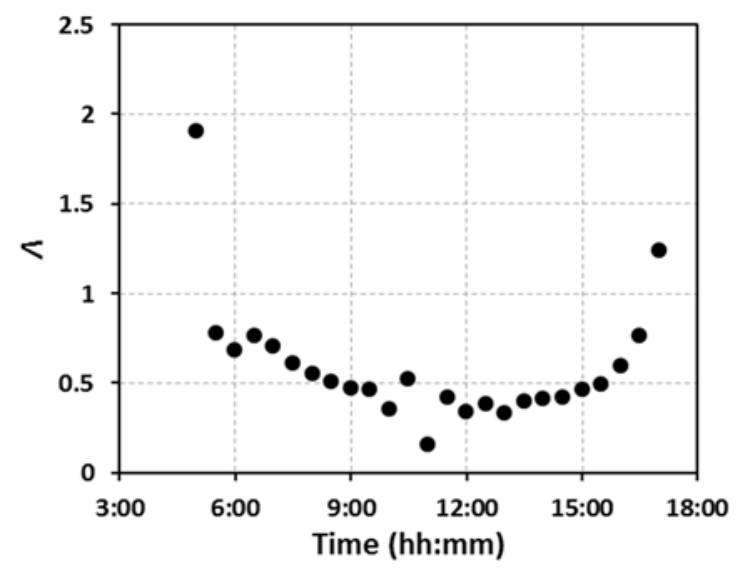

Figure 7. Diurnal $\Lambda$ behavior during the image acquisition day. 
According to Cammalleri et al. [36], comparing the stomata closure hourly behavior of different days, characterized by a regular $\Lambda$ shape, revealed that the minimum value is not attributable to any stoma closure.

Thus, this minimum could be due to environmental factors that showed high variability during the morning. In particular, wind speed and direction changed abruptly at approximately 10:00-10:30 a.m., with the former increasing from $1.1 \mathrm{~ms}^{-1}$ on the average between 8:00 and 10:00 a.m. to $2.9 \mathrm{~ms}^{-1}$ on the average between 10:30 a.m. and 12:00 p.m. A direct consequence of the wind change is a difference in the footprint's size and position where turbulent fluxes originate. $F P_{0.70}$ increased from 32 to $98 \mathrm{~m}$ between the first and last acquisitions due to an increase in wind speed (Table 1). During the morning, $F P_{0.70}$ was $40 \mathrm{~m}$ between approximately 8.00 and 9:30 a.m., and it increased to $81 \mathrm{~m}$ between 10:30 a.m. and midday. Moreover, the average direction changed from the southwest $\left(230^{\circ}\right.$ clockwise, $\mathrm{CW}$, from the north) to the west $\left(279^{\circ} \mathrm{CW}\right)$. The wind change affected the distance making the maximum contribution to the measured turbulent fluxes. This was $7 \mathrm{~m}$ in the first part of the morning and then increased up to $15 \mathrm{~m}$ during the second part.

The time required by the turbulent fluxes to reach the open path sensor from the source area range between 5 (fluxes originating at $X_{\max }$ at 12.00 p.m., Table 1 ) and $40 \mathrm{~s}$ (fluxes originating at $F P_{0.70}$ at 8.00 a.m.). Thus, the quantified time shift should not be considered as an EC measurement artifact.

Table 1. Half hour values of wind speed and direction ( 2 nd and 3 rd columns), $X_{\max }$ (4th column), FP0.70 (5th column), from 8:00 a.m. to 12:00 p.m. during the image acquisition day. Average values during the first part (8:00-10:00 a.m.) and the second part (10:30 a.m.-12:00 p.m.) of the morning.

\begin{tabular}{ccccc}
\hline Time & Wind Speed & Wind Direction & $\boldsymbol{X}_{\mathbf{m a x}}$ & $\boldsymbol{F P}_{\mathbf{0 . 7 0}}$ \\
\hline$(\mathrm{hh}: \mathrm{mm})$ & $\left(\mathrm{m} \cdot \mathrm{s}^{-1}\right)$ & $\left({ }^{\circ} \mathrm{CW}\right.$ from $\left.\mathrm{N}\right)$ & $(\mathrm{m})$ & $(\mathrm{m})$ \\
$8: 00$ & 0.80 & 246 & 6 & 32 \\
$8: 30$ & 1.40 & 247 & 9 & 49 \\
$9: 00$ & 1.29 & 230 & 8 & 45 \\
$9: 30$ & 1.15 & 211 & 7 & 38 \\
$10: 00$ & 1.00 & 214 & 6 & 35 \\
$10: 30$ & 1.99 & 287 & 11 & 60 \\
$11: 00$ & 2.68 & 276 & 13 & 72 \\
$11: 30$ & 3.43 & 275 & 17 & 93 \\
$12: 00$ & 3.67 & 278 & 18 & 98 \\
8:00-10:00 & 1.1 & 230 & 7 & 40 \\
10:30-12:00 & 2.9 & 279 & 15 & 81 \\
\hline
\end{tabular}

\subsection{Diachronic Analysis}

The 30 min weekly averaged diurnal behavior of $\lambda E T$, based on the $R_{s}$ approach (Figure 8 , empty dots) and on the $\Lambda$ approach (black dots), follows the same pattern of changes during the daytime (weekly average of the five selected weeks), as the hourly $\lambda E T$ based on the $\Lambda$ approach overestimated $\lambda E T$ before 7:00 a.m. and after 4:00 p.m. However, the hourly $\lambda E T$ based on the $R_{S}$ approach underestimated $\lambda E T$ during the same times. By considering an acceptable variability (dashed lines) of $\pm 15 \%$ of the EC $\lambda E T_{\beta R}$ (Figure 8 , black line), the resulting best remote sensing acquisition time ranges between 10:00 a.m. and 4:00 p.m.

Coherently, the analysis of the temporal variability of $C V$ (Figure 9) reveals that, between 8:30 a.m. and 2:00 p.m., half-hourly $\lambda E T$ is representative of hourly $\lambda E T(C V<0.15) . C V$ is lower $(0.02)$ between 10:00 and 11:30 a.m., which aligns with findings from previous studies. 

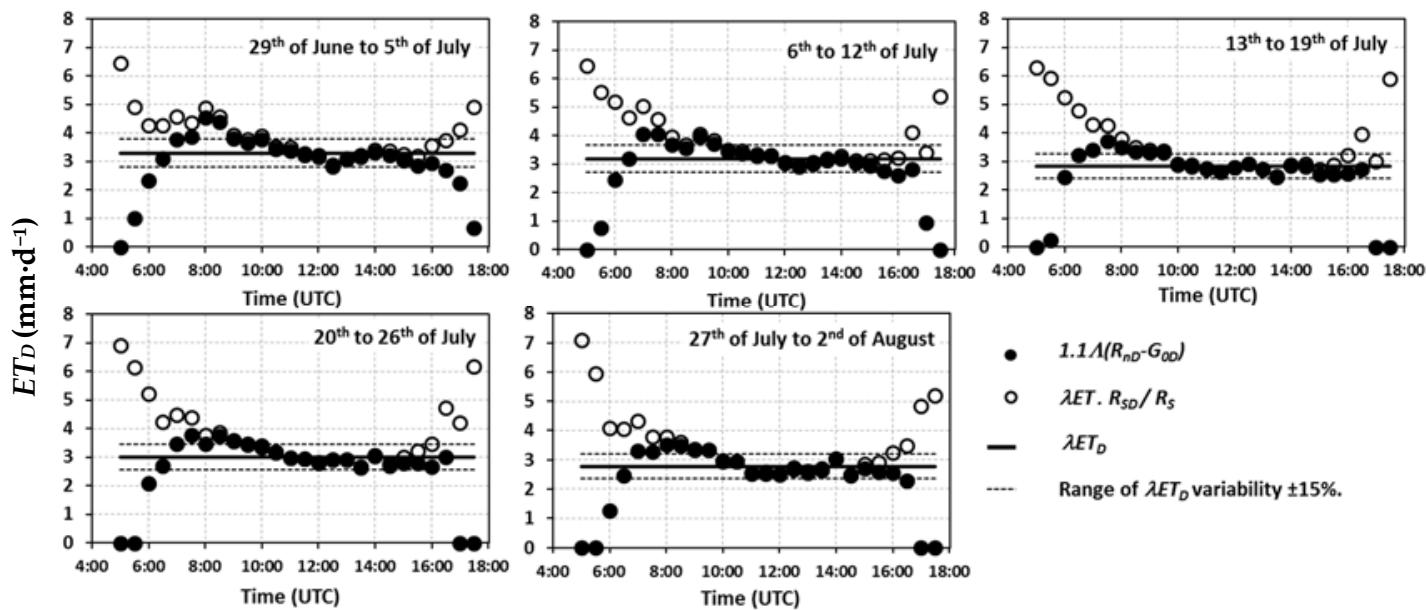

Figure 8. The weekly 30 min averaged diurnal changes of (black dots) and (empty dots) with the $E T_{D}$ measured with EC tower and the range of variability $\pm 15 \%$.

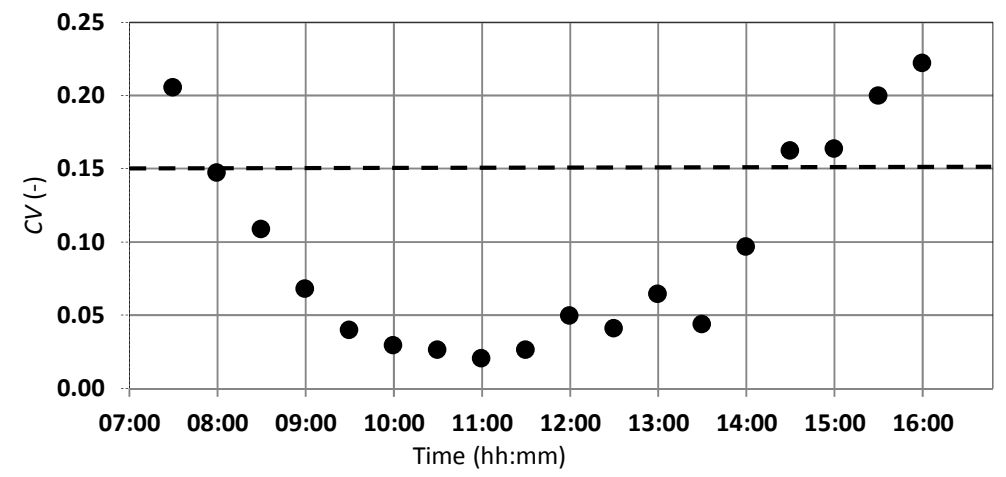

Figure 9. Half hourly temporal variability of the coefficient of variation, $C V$ (unitless), evaluated over the time from 29 June to 2 August. The over-imposed dash line indicates a $15 \%$ limit of acceptability.

\subsection{Spatial Resolution Analysis}

Once the surface energy balance was applied, $\lambda E T$ values were compared to those measured with the flux tower and added at the image acquisition times $\left(194.8,224.3,189.7\right.$, and $253.3 \mathrm{~W} \cdot \mathrm{m}^{-2}$ at 8:23, 9:14; 10:00, and 10:18 a.m., respectively). $E T_{D}$ was evaluated through both the $\Lambda$ self-preservation and $R_{S}$-based approaches at re-sampled spatial resolutions characterizing the canopy sizes and orchard structure $(2,5$, and $10 \mathrm{~m})$. Results show (Figure 10) that the second approach generally gives better results.

When $\Lambda$ does not exhibit regular behavior, the self-preservation approach provided overestimated retrievals. In particular, compared to the $E T_{D, \beta R}$ flux tower measurements ( $2.7 \mathrm{~mm}$, surface energy balance closure), good alignments were found at 10:00 a.m. (2.83 mm, $R_{s}$ approach) and 10:18 a.m. (2.76 mm, $\Lambda$ approach) at the $5 \mathrm{~m}$ spatial resolution. However, at the 2 and $10 \mathrm{~m}$ spatial resolutions, no good alignments were found, likely due to the application of a single source model.

The data do not fit the in situ SF measurements at lower spatial resolution ( 2 and $5 \mathrm{~m})$, with the values closest to the daily flow $(2.55 \mathrm{~mm})$ at 9:14 a.m. $\left(2.37 \mathrm{~mm}, R_{s}\right.$ approach) and 10:18 a.m. $(2.76 \mathrm{~mm}$, $\Lambda$ approach) at $5 \mathrm{~m}$ of spatial resolution. 


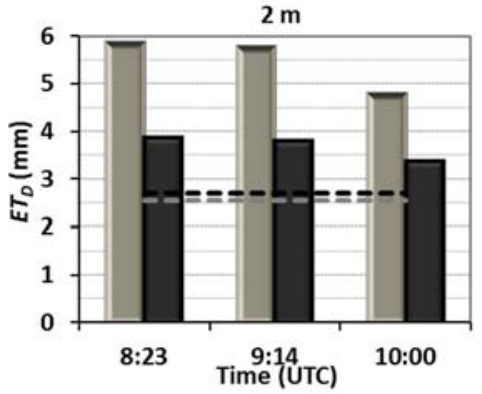

(a)

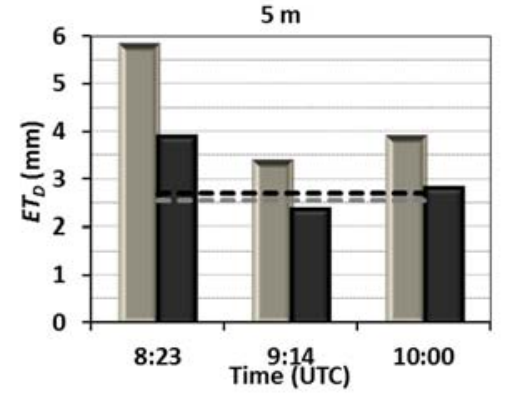

(b)

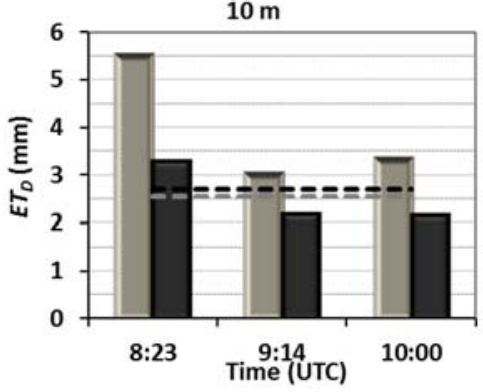

(c)

Figure 10. Spatially averaged $E T_{D}$ on the footprint area, calculated using the integration factors based on $\Lambda$ (grey bars) and $R_{S}$ (black bars), during the image acquisition day for different input spatial

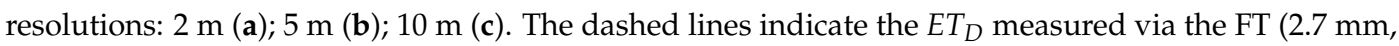
black line) and the T24 measured via the SF method (2.55 mm, grey line).

\subsection{Absolute Difference Analysis (FT)}

Flux tower observations were used to measure the absolute errors of $\lambda E T$ and $E T_{D}$. Errors affecting daily evapotranspiration were computed over both the self-preservation and the $R_{S}$ techniques. Absolute errors within the range of \pm 0.15 (Figure 10, bands bounded by the dashed grey lines) were compatible to flux tower closure errors acceptability [28].

Acquisition at 8:23 a.m. led to worse results (Figure 11a), whereas acquisitions at 9:14 and 10:00 a.m. gave better estimates (at 2 and $5 \mathrm{~m}$ spatial resolutions). Integrating daily values based on the hypothesis of the constant evaporative fraction confirms the best results at 9:14 and 10:00 a.m. However, more accurate $A D_{\Lambda}$ values (Figure $11 \mathrm{~b}$ ) were found at 5 and $10 \mathrm{~m}$ spatial resolutions. Inaccuracies are probably due to the diurnal variability of evaporative fraction during the image acquisition day at 8:23 and 9:14 a.m.

More accurate daily evapotranspiration estimates are obtained through the $R_{\mathrm{S}}$ approach (at all the acquisition times), with best estimates at 10:00 a.m. at $5 \mathrm{~m}$ spatial resolution $\left(A D_{R s}=0.05\right)$. Even though error analysis cannot be considered conclusive, it seems to indicate the best acquisition time at 10:00 a.m. with a spatial resolution close to the average plant crown size.

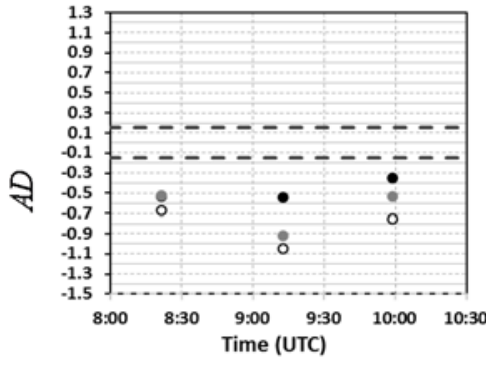

(a)

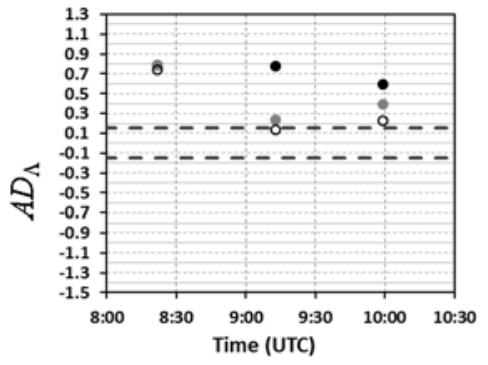

(b)

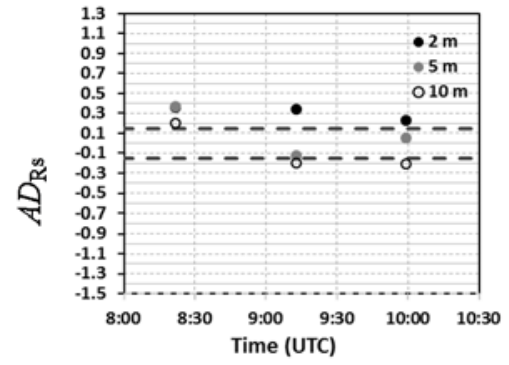

(c)

Figure 11. Absolute difference, $A D$ (unitless), of $\lambda E T(\mathbf{a})$, and $E T_{D}$ based on $\Lambda$ scaling factor (b), and $R_{\mathcal{S}}$ scaling factor (c) during the image acquisition day. The two dashed grey lines indicate an acceptable range of variability of $\pm 15 \%$.

\section{Conclusions}

This research focused on the use of the eddy covariance latent heat flux and sap flow transpiration to validate a surface energy balance model. Two time upscaling approaches to estimate daily evapotranspiration were tested at different spatial resolutions and acquisition times. Daily values 
were retrieved by assuming the self-preservation of the evaporative fraction in a diurnal cycle or by considering the proportionality with shortwave solar radiation at ground level.

Measures of transpiration via sap flow appear stable if compared with latent heat flux measured via a flux tower, even though sap flow measurements need to be accurately upscaled to manage transpiration in order to be used for validation.

The analysis confirmed that eddy covariance latent heat flux is suitable for the validation at both the instantaneous and the daily rate. A time lag was found between latent heat flux at the canopy and sap flow at the trunk; it lasted approximately $2.5 \mathrm{~h}$ within this study.

The time lag plays a role during validation since sap flow transpiration can be compared in a straightforward manner to surface energy balance estimates, if surface energy balance is applied on images acquired close to solar noon or if daily evapotranspiration is the aim of the validation.

Diachronic and spatial resolution analyses show that only a limited number of combinations can provide for accurate estimates of hourly and/or daily actual evapotranspiration. The upscaling approach based on diurnal evaporative fraction produces inaccuracies when estimating daily evapotranspiration, which is likely due to the irregular behavior of the evaporative fraction. However, the solar radiation technique yields better results at all acquisition times. On the whole, the analysis suggests a best acquisition time at $\approx 10: 00 \mathrm{a}$.m. with a spatial resolution comparable to the average tree crown size $(5 \mathrm{~m})$. As such, the $C V$ of EC $\lambda E T$ reveals that half-hourly $\lambda E T$ is representative of hourly values between 10:00 and 11:30 a.m. where $C V<0.02$.

Further investigations are required to determine how time lag varies with conductance reduction factors, including the plant's available soil water content.

Acknowledgments: This work was partly funded by the Università di Pisa (Fondi di Ateneo, 2016) and by Università degli Studi di Palermo (Progetto MITO: Informazioni Multimediali per Oggetti Territoriali PAC01_00119, CUP B72F13000300001. Linea intervento "Ricerca e Innovazione"-Azione "Potenziamento Strutturale"). The authors wish to thank Giorgio Manno and Mario Tulone for their help in acquiring the remote sensing data. The authors express their gratitude to the "Tenuta Rocchetta-Azienda Agricola Angela Consiglio" farm for kindly hosting the experiment.

Author Contributions: Antonino Maltese, Fulvio Capodici and Giuseppe Ciraolo designed the proximity sensing platform and acquisitions; Giovanni Rallo measured the soil physical properties, designed the tree sap flow acquisitions and the field upscaling procedure; Giuseppe Ciraolo and Antonino Maltese designed the eddy covariance acquisitions, Fulvio Capodici wrote the software code; Antonino Maltese, Fulvio Capodici, Hassan Awada and Giovanni Rallo processed the data; Goffredo La Loggia coordinated the research group and supervised the research. All the authors analyzed the results, wrote and approved the paper

Conflicts of Interest: The authors declare no conflict of interest. The founding sponsors had no role in the design of the study; in the collection, analyses, or interpretation of data; in the writing of the manuscript; or in the decision to publish the results.

\section{Appendix A}

List of Variables
$c_{\mathrm{f}}$
$q$
$r^{2}$
$t$
$A D$
$A D_{\Lambda}$
$A D_{R s}$
$A_{P}$
$E T$
$E T_{D}$
$E T_{D, \beta R}$
$E T_{D, R s}$
$E T_{D, \Lambda}$
$F P_{0.70}$

$\begin{array}{ll}\text { time unit conversion factor }(=86,400) & \left(\mathrm{s} \cdot \mathrm{d}^{-1}\right) \\ \text { sap flux within } S & \left(\mathrm{~m}^{3} \cdot \mathrm{s}^{-1}\right) \\ \text { determination coefficient } & (-) \\ \text { half-hourly time step } & (\mathrm{s}) \\ \text { absolute difference in the estimate of } \lambda E T & \left(\mathrm{~mm} \cdot \mathrm{d}^{-1}\right) \\ A D \text { in the estimate of } E T_{D} \text { based on } \Lambda & \left(\mathrm{mm} \cdot \mathrm{d}^{-1}\right) \\ A D \text { in the estimate of } E T_{D} \text { based on } R_{S} & \left(\mathrm{~mm} \cdot \mathrm{d}^{-1}\right) \\ \text { plant pertinence area } & (\mathrm{m}) \\ \text { actual hourly evapotranspiration } & \left(\mathrm{mm} \cdot \mathrm{d}^{-1}\right) \\ \text { actual daily evapotranspiration } & \left(\mathrm{mm} \cdot \mathrm{d}^{-1}\right) \\ E T_{D} \text { adjusted by preserving } \beta_{R} & \left(\mathrm{~mm} \cdot \mathrm{d}^{-1}\right) \\ E T_{D} \text { based on } R_{S} \text { as integration factor } & \left(\mathrm{mm} \cdot \mathrm{d}^{-1}\right) \\ E T_{D} \text { based on the self-preservation hypothesis of } \Lambda & \left(\mathrm{mm} \cdot \mathrm{d}^{-1}\right) \\ \text { average footprint determining } 70 \% \text { of the fluxes } & (\mathrm{m})\end{array}$




\begin{tabular}{|c|c|c|}
\hline$G_{0}$ & soil heat flux at ground level at the acquisition time & $\left(\mathrm{W} \cdot \mathrm{m}^{-2}\right)$ \\
\hline$H$ & sensible heat flux & $\left(\mathrm{W} \cdot \mathrm{m}^{-2}\right)$ \\
\hline$L A I$ & leaf Area Index & $\left(\mathrm{m}^{2} \cdot \mathrm{m}^{-2}\right)$ \\
\hline$L A I_{p}$ & LAI of a single plant & $\left(\mathrm{m}^{2} \cdot \mathrm{m}^{-2}\right)$ \\
\hline$R_{n}$ & net radiation at the acquisition time & $\left(\mathrm{W} \cdot \mathrm{m}^{-2}\right)$ \\
\hline$R_{n, D}$ & daily net radiation & $\left(\mathrm{W} \cdot \mathrm{m}^{-2}\right)$ \\
\hline$R_{S}$ & hourly incoming shortwave radiation & $\left(\mathrm{W} \cdot \mathrm{m}^{-2}\right)$ \\
\hline$S$ & the cross-sectional area of conducting sapwood & $\left(\mathrm{m}^{2}\right)$ \\
\hline$T$ & hourly transpiration of an entire field & $\left(\mathrm{mm} \cdot \mathrm{d}^{-1}\right)$ \\
\hline$T_{p}$ & hourly transpiration of a single plant & $\left(\mathrm{mm} \cdot \mathrm{d}^{-1}\right)$ \\
\hline$X_{\max }$ & distance determining the maximum flux contribution & $(\mathrm{m})$ \\
\hline$\alpha$ & multiplicative coefficient of the sap flow Equation (5) & $\left(\mathrm{m} \cdot \mathrm{s}^{-1}\right)$ \\
\hline$\beta_{\mathrm{R}}$ & Bowen ratio & $(-)$ \\
\hline$\beta$ & power coefficient of the sap flow Equation (5) & $(-)$ \\
\hline$\Delta T$ & temperature difference between two sap flow probes & $(\mathrm{K})$ \\
\hline$\Delta T_{\max }$ & maximum $\Delta T$ occurring when sap velocity is minimum & $(\mathrm{K})$ \\
\hline$\Lambda$ & hourly evaporative fraction & $(-)$ \\
\hline$\Lambda_{\mathrm{d}}$ & average diurnal evaporative fraction & $(-)$ \\
\hline$\lambda$ & latent heat of vaporization & $\left(\mathrm{MJ} \cdot \mathrm{kg}^{-1}\right)$ \\
\hline$\lambda E T$ & actual hourly latent heat flux & $\left(\mathrm{W} \cdot \mathrm{m}^{-2}\right)$ \\
\hline$\lambda E T_{\beta R}$ & $\lambda E T$ adjusted by preserving $\beta_{R}$ & $\left(\mathrm{~W} \cdot \mathrm{m}^{-2}\right)$ \\
\hline$\rho_{w}$ & water density & $\left(\mathrm{kg} \cdot \mathrm{m}^{-3}\right)$ \\
\hline \multicolumn{3}{|c|}{ List of Acronyms } \\
\hline ASD & analytical spectral device & \\
\hline CCD & charge coupled device & \\
\hline $\mathrm{CW}$ & clockwise & \\
\hline EC & eddy covariance & \\
\hline EPSG & $\begin{array}{l}\text { European Petroleum Survey Group geodetic parameters } \\
\text { dataset }\end{array}$ & \\
\hline FT & flux tower & \\
\hline IRGA & infrared gas analyzer & \\
\hline IRTS-P & precision infrared thermocouple sensor & \\
\hline $\mathrm{P}_{1}, \mathrm{P}_{2}, \mathrm{P}_{3}$ & olives trees where sap flow probes were installed & \\
\hline SEBAL & surface energy balance algorithm for land & \\
\hline SF & sap flow & \\
\hline SFS2 & sapflow sensor & \\
\hline TIR & thermal infrared & \\
\hline USDA & United States Department of Agriculture & \\
\hline
\end{tabular}

\section{References}

1. Khadra, R.; Moreno, M.A.; Awada, H.; Lamaddalena, N. Energy and Hydraulic Performance-Based Management of Large-Scale Pressurized Irrigation Systems. Water Resour. Manag. 2016, 30, 3493-3506. [CrossRef]

2. Ciraolo, G.; Cammalleri, C.; Capodici, F.; D’Urso, G.; Maltese, A. Mapping evapotranspiration on vineyards: A comparison between Penman-Monteith and energy balance approaches for operational purposes. In Proceedings of the SPIE-The International Society for Optical Engineering, Edinburgh, UK, 23 October 2012; Volume 8531, pp. 85310Q1-85310Q9.

3. Verstraeten, W.W.; Veroustraete, F.; Feyen, J. Assessment of evapotranspiration and soil moisture content across different scales of observation. Sensors 2008, 8, 70-117. [CrossRef] [PubMed]

4. Cammalleri, C.; Rallo, G.; Agnese, C.; Ciraolo, G.; Minacapilli, M.; Provenzano, G. Combined use of eddy covariance and sap flow techniques for partition of et fluxes and water stress assessment in an irrigated olive orchard. Agric. Water Manag. 2013, 120, 89-97. [CrossRef] 
5. Granier, A. Une nouvelle méthode pour la mesure du flux de sève brute dans le tronc des arbres. Ann. Sci. For. 1985, 42, 193-200. [CrossRef]

6. Derbyshire, S.H. Atmospheric boundary layer flows-their structure and measurement. by J. C. Kaimal and J. J. Finnigan. Oxford University Press. 1994. pp. 289. ISBN 019506239 6. Q. J. R. Meteorol. Soc. 1995, 121, 1177. [CrossRef]

7. Chávez, J.L.; Neale, C.M.U.; Prueger, J.H.; Kustas, W.P. Daily evapotranspiration estimates from extrapolating instantaneous airborne remote sensing et values. Irrig. Sci. 2008, 27, 67-81. [CrossRef]

8. Bastiaanssen, W.G.M.; Menenti, M.; Feddes, R.A.; Holtslag, A.A.M. A remote sensing surface energy balance algorithm for land (SEBAL): 1. Formulation. J. Hydrol. 1998, 212-213, 198-212. [CrossRef]

9. Cammalleri, C.; Ciraolo, G.; La, L.; Maltese, A. Daily evapotranspiration assessment by means of residual surface energy balance modeling: A critical analysis under a wide range of water availability. J. Hydrol. 2012, 452-453, 119-129. [CrossRef]

10. Crago, R.D. Conservation and variability of the evaporative fraction during the daytime. J. Hydrol. 1996, 180, 173-194. [CrossRef]

11. Jackson, R.D.; Hatfield, J.L.; Reginato, R.J.; Idso, S.B.; Pinter, J. Estimation of daily evapotranspiration from one time-of-day measurements. Agric. Water Manag. 1983, 7, 351-362. [CrossRef]

12. Meijninger, W.M.L.; Beyrich, F.; Lüdi, A.; Kohsiek, W.; De Bruin, H.A.R. Scintillometer-based turbulent fluxes of sensible and latent heat over a heterogeneous land surface-A contribution to LITFASS-2003. Bound. Layer Meteorol. 2006, 121, 89-110. [CrossRef]

13. Opperman, D.P.J.; Roberts, B.R. Evapotranspiration studies on themeda triandra under field conditions: A study in lysimeter methodology [Evapotranspirasie-studies op themeda triandra onder veld-toestande: 'N studie in lisimeter metodes]. Proc. Annu. Congr. Grassl. Soc. South. Afr. 1975, 10, 103-109. [CrossRef]

14. Castellví, F.; Cammalleri, C.; Ciraolo, G.; Maltese, A.; Rossi, F. Daytime sensible heat flux estimation over heterogeneous surfaces using multitemporal land-surface temperature observations. Water Resour. Res. 2016, 52, 3457-3476. [CrossRef]

15. Anderson, M.C.; Norman, J.M.; Diak, G.R.; Kustas, W.P.; Mecikalski, J.R. A two-source time-integrated model for estimating surface fluxes using thermal infrared remote sensing. Remote Sens. Environ. 1997, 60, 195-216. [CrossRef]

16. Bastiaanssen, W.G.M. SEBAL-based sensible and latent heat fluxes in the irrigated Gediz Basin, Turkey. J. Hydrol. 2000, 229, 87-100. [CrossRef]

17. Bastiaanssen, W.G.M.; Noordman, E.J.M.; Pelgrum, H.; Davids, G.; Thoreson, B.P.; Allen, R.G. SEBAL model with remotely sensed data to improve water-resources management under actual field conditions. J. Irrig. Drain. Eng. 2005, 131, 85-93. [CrossRef]

18. Gentine, P.; Entekhabi, D.; Chehbouni, A.; Boulet, G.; Duchemin, B. Analysis of evaporative fraction diurnal behaviour. Agric. For. Meteorol. 2007, 143, 13-29. [CrossRef]

19. Malek, E. Night-time evapotranspiration vs. daytime and 24 h evapotranspiration. J. Hydrol. 1992, 138, 119-129. [CrossRef]

20. Hoedjes, J.C.B.; Chehbouni, A.; Jacob, F.; Ezzahar, J.; Boulet, G. Deriving daily evapotranspiration from remotely sensed instantaneous evaporative fraction over olive orchard in semi-arid Morocco. J. Hydrol. 2008, 354, 53-64. [CrossRef]

21. Allen, R.G.; Tasumi, M.; Trezza, R. Satellite-based energy balance for mapping evapotranspiration with internalized calibration (METRIC)—Model. J. Irrig. Drain. Eng. 2007, 133, 380-394. [CrossRef]

22. Lhomme, J.-P.; Elguero, E. Examination of evaporative fraction diurnal behaviour using a soil-vegetation model coupled with a mixed-layer model. Hydrol. Earth Syst. Sci. 1999, 3, 259-270. [CrossRef]

23. Brutsaert, W.; Sugita, M. Application of self-preservation in the diurnal evolution of the surface energy budget to determine daily evaporation. J. Geophys. Res. 1992, 97, 18377-18382. [CrossRef]

24. Franks, S.W.; Beven, K.J. Estimation of evapotranspiration at the landscape scale: A fuzzy disaggregation approach. Water Resour. Res. 1997, 33, 2929-2938. [CrossRef]

25. Allen, R.G.; Pereira, L.S.; Raes, D.; Smith, M. Crop Evapotranspiration-Guidelines for Computing Crop Water Requirements-FAO Irrigation and Drainage Paper 56; FAO_Food and Agriculture Organization of the United Nations: Rome, Italy, 1998; p. 326.

26. Foken, T.; Wimmer, F.; Mauder, M.; Thomas, C.; Liebethal, C. Some aspects of the energy balance closure problem. Atmos. Chem. Phys. 2006, 6, 4395-4402. [CrossRef] 
27. Prueger, J.H.; Hatfield, J.L.; Kustas, W.P.; Hipps, L.E.; MacPherson, J.I.; Neale, C.M.U.; Eichinger, W.E.; Cooper, D.I.; Parkin, T.B. Tower and aircraft eddy covariance measurements of water vapor, energy and carbon dioxide fluxes during SMACEX. J. Hydrometeorol. 2005, 6, 954-960. [CrossRef]

28. Allen, R.G.; Pereira, L.S.; Howell, T.A.; Jensen, M.E. Evapotranspiration information reporting: I. Factors governing measurement accuracy. Agric. Water Manag. 2011, 98, 899-920. [CrossRef]

29. Schuepp, P.H.; Leclerc, M.Y.; MacPherson, J.I.; Desjardins, R.L. Footprint prediction of scalar fluxes from analytical solutions of the diffusion equation. Bound. Layer Meteorol. 1990, 50, 355-373. [CrossRef]

30. Granier, A. Evaluation of Transpiration in a Douglas-Fir Stand by Means of Sap Flow Measurements. Tree Physiol. 1987, 3, 309-319. [CrossRef] [PubMed]

31. Motisi, A.; Consoli, S.; Papa, R.; Cammalleri, C.; Rossi, F.; Minacapilli, M.; Rallo, G. Eddy covariance and sap flow measurement of energy and mass exchanges of woody crops in a Mediterranean environment. Acta Hortic. 2012, 951, 121-128. [CrossRef]

32. Rallo, G.; Provenzano, G. Modelling eco-physiological response of table olive trees (Olea europaea L.) To soil water deficit conditions. Agric. Water Manag. 2013, 120, 79-88. [CrossRef]

33. Phillips, N.; Nagchaudhuri, A.; Oren, R.; Katul, G. Time constant for water transport in loblolly pine trees estimated from time series of evaporative demand and stem sapflow. Trees Struct. Funct. 1997, 11, 412-419. [CrossRef]

34. Kumagai, T. Modeling water transportation and storage in sapwood-Model development and validation. Agric. For. Meteorol. 2001, 109, 105-115. [CrossRef]

35. Ford, C.R.; Goranson, C.E.; Mitchell, R.J.; Will, R.E.; Teskey, R.O. Modeling canopy transpiration using time series analysis: A case study illustrating the effect of soil moisture deficit on Pinus taeda. Agric. For. Meteorol. 2005, 130, 163-175. [CrossRef]

36. Phillips, N.G.; Ryan, M.G.; Bond, B.J.; McDowell, N.G.; Hinckley, T.M.; Čermák, J. Reliance on stored water increases with tree size in three species in the Pacific Northwest. Tree Physiol. 2003, 23, 237-245. [CrossRef] [PubMed]

37. Bohrer, G.; Mourad, H.; Laursen, T.A.; Drewry, D.; Avissar, R.; Poggi, D.; Oren, R.; Katul, G.G. Finite element tree crown hydrodynamics model $(\mathrm{FETCH})$ using porous media flow within branching elements: A new representation of tree hydrodynamics. Water Resour. Res. 2005, 41, 1-17. [CrossRef]

38. Phillips, N.G.; Scholz, F.G.; Bucci, S.J.; Goldstein, G.; Meinzer, F.C. Using branch and basal trunk sap flow measurements to estimate whole-plant water capacitance: Comment on Burgess and Dawson (2008). Plant Soil 2009, 315, 315-324. [CrossRef]

39. Dichio, B.; Xiloyannis, C.; Sofo, A.; Montanaro, G. Osmotic regulation in leaves and roots of olive trees during a water deficit and rewatering. Tree Physiol. 2006, 26, 179-185. [CrossRef] [PubMed]

40. Fernández, J. Plant-Based Methods for Irrigation Scheduling of Woody Crops. Horticulturae 2017, 3, 35. [CrossRef]

41. Gentine, P.; Entekhabi, D.; Polcher, J. The Diurnal Behavior of Evaporative Fraction in the Soil-Vegetation-Atmospheric Boundary Layer Continuum. J. Hydrometeorol. 2011, 12, 1530-1546. [CrossRef]

(C) 2018 by the authors. Licensee MDPI, Basel, Switzerland. This article is an open access article distributed under the terms and conditions of the Creative Commons Attribution (CC BY) license (http:// creativecommons.org/licenses/by/4.0/). 